\title{
Diagnostic value of lumbar puncture among infants and children presenting with fever and convulsions
}

Abdelrahim Abdrabou Sadek ${ }^{1}$, Mostafa Ashry Mohamad², Safaa Hussin Ali ${ }^{3}$, Ismail Abd Al-Aleem Hassan ${ }^{4}$, Mohammad Fouad Hussein ${ }^{5}$

${ }^{1}$ Assistant Professor and Head of Pediatric Neurology Unit, Department of Pediatrics, Faculty of Medicine, Sohag University, Sohag, Egypt

${ }^{2}$ Lecturer, Department of Pediatrics, Faculty of Medicine, Sohag University, Sohag, Egypt

${ }^{3}$ Assistant Professor, Pediatric Cardiology Unit, Department of Pediatrics, Faculty of Medicine, Sohag University, Sohag, Egypt

${ }^{4}$ Assistant Professor, Department of Pediatrics, Faculty of Medicine, Sohag University, Sohag, Egypt

${ }^{5}$ Assistant Lecturer, Department of Pediatrics, Faculty of Medicine, Aswan University, Aswan, Egypt

\section{Type of article: Original}

\begin{abstract}
Introduction: Central nervous system (CNS) infections can be categorized according to the nature of the infectious pathogen into viral, bacterial, protozoan, or fungal. The diagnosis of diffuse CNS infections depends on examination of cerebrospinal fluid (CSF) obtained by lumbar puncture (LP). The aim of this work was to determine the diagnostic value of CSF analysis in infants and children presenting with fever and convulsions.

Methods: Detailed clinical data of infants and children included in this study were collected with special reference to the course and duration of the illness, description of the convulsions, consciousness level, signs of increased intracranial pressure, and signs of meningeal irritation. Lumbar puncture and chemical and bacteriological analyses of the obtained cerebrospinal fluid were done for all of the children.

Results: The total number of children included in the study was 85, they had a median age 19 months, and $88 \%$ of them had generalized convulsions. CSF examination revealed that $20 \%$ had abnormal physical findings, while $23.5 \%$ had abnormal white blood cell count (WBC) (CSF Pleocytosis). CSF cultures were done in three cases with the highest White blood cells (WBCs), and streptococcus pneumoniae was present in all three cases.

Conclusion: This study found that CNS infections are not uncommon in infants and children presenting with fever and convulsions in our locality, and acute bacterial meningitis cannot be excluded. However, its presence in the absence of clinical symptoms and signs of meningeal irritation is a remote possibility, but it should always be considered.
\end{abstract}

Keywords: cerebrospinal fluid, meningitis, encephalitis, lumbar puncture

\section{Introduction}

Infection of the CNS is the most common cause of fever associated with signs and symptoms of CNS disease in children. Many different pathogens can invade and damage the developing or mature CNS. Nonetheless, specific pathogens are identifiable and are influenced by the age and immune status of the host and the epidemiology of the pathogen. In general, viral infections of the CNS are much more common than bacterial infections, which, in turn, are more common than fungal and parasitic infections (1). Regardless of etiology, most patients with CNS infections have similar clinical manifestations. Common symptoms include headache, nausea, vomiting, anorexia, restlessness, altered state of consciousness, and irritability; most of these symptoms are nonspecific. Furthermore, common signs of CNS infections include fever, photophobia, neck pain and rigidity, obtundation, stupor, coma, seizures, and focal neurologic deficits (1). In general terms, CNS infections can be categorized according to the nature of the infectious pathogen into viral, bacterial, protozoan, or fungal and by the location of the infection, whether parenchymal,

\section{Corresponding author:}

Dr. Abdelrahim A. Sadek, Pediatric Neurology Unit, Pediatric Department, Sohag University, Sohag, Egypt. Tel: +20.1065067057; Fax: +20934602963, E-mail: abdoneurology@yahoo.com and wafaaderm78@yahoo.com Received: January 12, 2016, Accepted: March 17, 2016, Published: April 2016 iThenticate screening: March 17, 2016, English editing: April 02, 2016, Quality control: April 08, 2016 (C) 2016 The Authors. This is an open access article under the terms of the Creative Commons Attribution-NonCommercialNoDerivs License, which permits use and distribution in any medium, provided the original work is properly cited, the use is non-commercial and no modifications or adaptations are made. 
meningeal, or vascular (2). The diagnosis of diffuse CNS infections depends on examination of cerebrospinal fluid (CSF) obtained by lumbar puncture (LP) (1). Streptococcus pneumoniae, Neisseria meningitides, and Haemophilus influenzae type $\mathrm{b}(\mathrm{Hib})$ are the most common causes of bacterial meningitis in infants and young children worldwide. Children older than 5 and adolescents generally have $S$. pneumoniae and $N$. meningitides as the predominant causes of bacterial meningitis (3). Most of the bacteria that cause invasive diseases have a polysaccharide capsule, and this is the case for meningitis in children (4). The age of the patient affects the manifestations of bacterial meningitis. Less than $50 \%$ of the children afflicted with meningitis experience neck stiffness, fever, and changes in their mental status, while only $5 \%$ of adults with bacterial meningitis show Kernig and Brudzinski signs. In children with bacterial meningitis, these symptoms are observed even less frequently. Signs of meningeal irritation, including neck stiffness and Brudzinski and Kernig signs are not specific to bacterial meningitis in children (5). The definitive diagnosis of bacterial meningitis requires a lumbar puncture. The analysis of CSF should include white blood cell (WBC) count; glucose and protein concentrations, gram stain, and cultures (6). Pleocytosis is a typical finding in bacterial meningitis, the WBC count usually is greater than $1000 \mathrm{cells} / \mathrm{mm} 3$, and there is a predominance of polymorphonuclear leukocytes. In neonates the glucose concentration is usually decreased with a CSF-to-serum glucose ratio of 0.6 or less, whereas, in children older than two months, the ratio is 0.4 or less. In both cases, however, an elevated protein concentration is usually observed (7). The lower level of detection of a gram-stained smear of CSF is about 105 colony-forming units $/ \mathrm{mL}$. In patients who have untreated bacterial meningitis, a positive CSF gram stain occurs in 80 to $90 \%$ of the patients (8). Encephalitis refers to the inflammation of the brain's parenchyma, and such swelling can be the result of the presence of various viruses and other microorganisms. Some cases of acute disseminated encephalomyelitis (ADEM), which often occur after infections or vaccinations, occur as an immune-mediated phenomenon (9). It is very common for children with viral encephalitis (VE) to be treated with IV acyclovir and broad range of antibiotics. Also, they may be treated for varying lengths of time before confirmation of the VE diagnosis is possible. Thus, the approach to making a diagnosis and the length and route of treatment with acyclovir often vary in these children (10). There is controversy concerning the use of lumbar puncture (LP) when CNS infections are suspected. Frequently, children are admitted and treatments for bacterial meningitis and encephalitis are initiated prior to performing LP. However, it is still essential to perform LP on these children when it is safe to do so to confirm the diagnosis and guide subsequent management (11). It should not be general practice to blindly administer anti-bacterial and anti-viral treatments to all patients with suspected CNS infection prior to LP because there is a risk of missing other diagnoses that may require alternative treatments (12). Since fever and convulsions are very frequent conditions encountered in the Pediatric Department, so our aim was to determine the diagnostic value of CSF analysis in infants and children presenting with fever and convulsions.

\section{Material and Methods}

\subsection{Study design}

This observational, hospital-based study was conducted in the emergency unit, the inpatient department, and the intermediate care unit at the pediatric department in Sohag University Hospital, Upper Egypt, during the period from December 2012 through November 2013. All Infants and children, from the age of one month to twelve years, who presented with fever and convulsions, were eligible for this study, but we excluded neonates, patients who had contraindications to lumbar puncture, such as those with suspected mass lesion of the brain, symptoms and signs of impending cerebral herniation, critical illness, skin infection at the site of the lumbar puncture, and thrombocytopenia with a platelet count $<20 \times 10^{9} / \mathrm{L}$. Informed consent of the parents of the children was acquired to conduct this research in addition to the approval of the Faculty of Medicine, Sohag University Ethics Committee. The study was conducted in accordance with the Code of Ethics of the World Medical Association (Declaration of Helsinki) for experiments on humans.

\subsection{Methods}

Detailed clinical data of the patients were collected, with special reference to onset, course, and duration of the illness, convulsion characteristics, presence of preceding illnesses, such as gastroenteritis, and complications, such as disturbed consciousness in addition to family history of convulsions. Furthermore, data from the examinations of the patients, especially the neurological system (conscious level, signs of increased intracranial pressure, signs of meningeal irritation, signs of lateralization, and other signs of neurological affection) also were collected. Lumbar puncture and CSF analysis (physical, chemical, and cytological aspects by a Cobas c 311 analyzer, Roche Diagnostics, Germany) were done for cases in which there were no contraindications. Brain computed tomography (CT) was done for cases with suspected intracranial lesions. 


\section{Results}

\subsection{Descriptive data of the studied patients}

During the study period, 85 children who presented with fever and convulsions were enrolled in this study. The median age was 19 months (age range from 2 months to 10 years) (Table 1). The majority of the patients (69 or $81 \%$ ) belonged to the age group of one month to two years. Concerning the gender distribution of the studied children, there was no significant difference as $39(46 \%)$ of the patients were males, and $46(54 \%)$ of the patients were females.

Table 1. Distribution of studied population according to different findings

\begin{tabular}{|c|c|c|c|}
\hline \multicolumn{2}{|l|}{ Variable } & $\mathrm{n}$ & $\%$ \\
\hline \multirow[t]{3}{*}{ Age } & 1 month- 2 years & 69 & 81.18 \\
\hline & $2-5$ years & 8 & 9.41 \\
\hline & $5-12$ years & 8 & 9.41 \\
\hline \multirow[t]{5}{*}{ Convulsion duration } & Less than 15 minutes & 26 & 30.59 \\
\hline & 15 minutes- $24 \mathrm{hr}$ & 33 & 38.82 \\
\hline & 1-3 days & 16 & 18.82 \\
\hline & 3-7 days & 9 & 10.59 \\
\hline & $\geq 7$ days & 1 & 1.18 \\
\hline \multirow[t]{2}{*}{ Fever } & Low grade $\left(<38.5^{\circ} \mathrm{C}\right)$ & 17 & 20 \\
\hline & High grade $\left(\geq 38.5^{\circ} \mathrm{C}\right)$ & 68 & 80 \\
\hline \multirow[t]{4}{*}{ Fever duration (day) } & $<1$ & 18 & 21.18 \\
\hline & $1-3$ & 31 & 36.47 \\
\hline & $3-7$ & 24 & 28.24 \\
\hline & $\geq 7$ & 12 & 14.12 \\
\hline \multirow[t]{2}{*}{ Diarrhea } & Not present & 53 & 62.35 \\
\hline & Present & 32 & 37.65 \\
\hline \multirow{4}{*}{ Diarrhea duration (day) } & $<1$ & 2 & 6.25 \\
\hline & $1-3$ & 11 & 34.38 \\
\hline & $3-7$ & 10 & 31.25 \\
\hline & $\geq 7$ & 9 & 28.13 \\
\hline \multirow[t]{2}{*}{ Vomiting } & Not present & 56 & 65.88 \\
\hline & Present & 29 & 34.12 \\
\hline \multirow[t]{4}{*}{ Vomiting duration (day) } & $<1$ & 2 & 6.90 \\
\hline & $1-3$ & 9 & 31.03 \\
\hline & $3-7$ & 12 & 41.38 \\
\hline & $\geq 7$ & 6 & 20.69 \\
\hline \multirow[t]{2}{*}{ Respiratory symptoms } & Not present & 78 & 91.76 \\
\hline & Present & 7 & 8.24 \\
\hline \multirow[t]{3}{*}{ Respiratory symptoms duration (day) } & $1-3$ & 5 & 71.43 \\
\hline & $3-7$ & 1 & 14.29 \\
\hline & $\geq 7$ & 1 & 14.29 \\
\hline
\end{tabular}

\subsection{Description of convulsions}

Nearly one third $(30.6 \%)$ of the patients had convulsions for less than a 15 -minute duration (Table 1). The great majority of patients $(88 \%)$ had generalized convulsions, $8 \%$ had focal convulsions, and only $4 \%$ had focal convulsions with secondary generalization. As regards recurrence, 55 patients $(64.7 \%)$ had recurrence of convulsions during the same illness, and there was no recurrence in the remaining $35.3 \%$ of the patients. Illnesses that preceded the convulsions were gastroenteritis in $37.65 \%$ of the patients, upper and lower respiratory tract infections in $8.24 \%$ of the patients. More than half of the patients had no preceding illness. Only four patients (4.7\%) had past histories of febrile convulsions and six patients $(7 \%)$ had past histories of epilepsy. A family history of convulsions existed for only 9 patients $(10.6 \%)$.

\subsection{Description of fever}

All patients had fevers of variable durations, and most of them (80\%) had high-grade fevers (Table 1). 


\subsection{Other presenting symptoms}

As regards presenting symptoms other than fever and convulsions, $37.6 \%$ of the patients had diarrhea, $34 \%$ had vomiting, and $8 \%$ had respiratory symptoms (Table 1 ).

\subsection{Systemic examination}

The head and neck examinations revealed that 15 patients had tonsillopharyngitis and/or otitis media, eight patients had signs of dehydration due to gastroenteritis, two had pallor, and only one patient had hydrocephalus. Chest examinations showed that $20 \%$ of the patients had signs of chest infection (bronchiolitis or pneumonia). Nine patients had signs of hemodynamic instability in cardiac examination. The results of abdominal examinations were unremarkable in the studied group of patients.

\subsection{Neurological examination}

Neurological examination focused on assessment of conscious level, presence of signs of increased intracranial pressure, signs of meningeal irritation, and signs of lateralization. The findings from the neurological examinations are summarized in Table 2 .

Table 2. Distribution of studied population according to neurological examination

\begin{tabular}{|l|l|l|l|}
\hline Characteristic & $\mathrm{n}$ & $\%$ \\
\hline Conscious level (Glasgow coma scale) & $15 / 15$ & 35 & 41.18 \\
\cline { 2 - 4 } & $8-14 / 15$ & 41 & 48.24 \\
\cline { 2 - 4 } & $3-7 / 15$ & 9 & 10.59 \\
\hline \multirow{2}{*}{ Signs of increased intracranial pressure } & Not present & 83 & 97.65 \\
\cline { 2 - 4 } & Present & 2 & 2.35 \\
\hline \multirow{3}{*}{ Signs of meningeal irritation } & Not present & 67 & 78.82 \\
\cline { 2 - 4 } & Neck rigidity \&/or retraction & 14 & 16.47 \\
\cline { 2 - 4 } & 2+Positive Brudziniski sign & 4 & 4.71 \\
\hline \multirow{2}{*}{ Signs of lateralization } & Not present & 83 & 97.65 \\
\cline { 2 - 4 } & Present & 2 & 2.35 \\
\hline
\end{tabular}

\subsection{CSF examination and culture}

CSF examination included physical, chemical, and microscopic examination. In the physical examination, most patients had clear aspect, and $20 \%$ had abnormal aspect (semi-turbid or turbid). Nearly the same was noticed for sediment. The color was normal in $86 \%$ of the patients. The findings of the CSF physical examination are presented in Table 3.

Table 3. Distribution of studied population according to physical CSF findings

\begin{tabular}{|l|l|l|l|}
\hline \multicolumn{2}{|l|}{ CSF findings } & $\mathrm{n}$ & $\%$ \\
\hline \multirow{3}{*}{ Aspect } & Clear & 67 & 78.82 \\
\cline { 2 - 4 } & Semi-turbid & 13 & 15.29 \\
\cline { 2 - 4 } & Turbid & 5 & 5.88 \\
\hline \multirow{3}{*}{ Sediment } & Nil & 65 & 76.47 \\
\cline { 2 - 4 } & White & 5 & 5.88 \\
\cline { 2 - 4 } & Red & 15 & 17.65 \\
\hline Color & Watery & 73 & 85.88 \\
\hline & White & 4 & 4.71 \\
\hline & Yellow & 6 & 7.06 \\
\hline & Red & 2 & 2.35 \\
\hline
\end{tabular}

Concerning chemical analysis of CSF, only $6 \%$ of patients had abnormal (decreased) glucose, and $24 \%$ had abnormal (increased) protein. Increased protein concentration was categorized into three groups. Microscopic examination indicated that $8 \%$ of patients had RBCs greater than 5/HPF. Normal WBC count was observed in $76.5 \%$ of the patients. Abnormal WBC count (CSF pleocytosis) was categorized into two groups, i.e., 5-1000/HPF (that is mostly due to viral infection) and 1000-10000/HPF (that is mostly due to bacterial infection). The results appeared to represent $20 \%$ (17 cases) for the first group and 3.5\% (three cases) for the second group. The results of differential WBC count were $71 \%$ all lymphocytes, $13 \%$ with lymphocyte predominance, and $16 \%$ with neutrophil 
predominance. CSF cultures were done for the three cases with the highest WBC count, and they indicated that the three children had streptococcus pneumoniae.

\subsection{CT brain scan}

CT brain scans were done for only 36 cases. It was not done for all cases because it was restricted to cases in which abnormal neurological examinations suggested possible intracranial pathology. Abnormalities were found in 10 cases. These abnormalities were brain edema in five cases, localized hypodense area(s) in two cases, diffuse brain atrophy in two cases, and hydrocephalus in one case.

\subsection{Comparing results between the normal and abnormal CSF groups}

\subsubsection{Age, gender, and convulsions}

When we compared the results of patients with normal CSF (65 cases) and those with abnormal CSF (CSF pleocytosis, 20 cases) according to age and gender, we found no significant difference between the two groups. Regarding convulsions, we found that the duration less than 15 minutes was present to a greater extent in patients with normal CSF (35.4\%) than in patients with abnormal CSF (10\%). Longer durations were present to a greater extent in patients with abnormal CSF (90\%). Generalized convulsions occurred in patients who had normal CSF $(92.3 \%)$ to a greater extent than in who had abnormal CSF $(75 \%)$. However, other distribution patterns occurred in the abnormal group (25\%) more than in the normal group (7.6\%). Recurrence during the same illness occurred more often in patients with abnormal CSF $(80 \%)$ than in the other patients $(60 \%)$. Preceding illness: no certain preceding illness was present in $65 \%$ of patients with abnormal CSF, which was more than the percentage in the group with normal CSF (50\%). Gastroenteritis occurred slightly more in patients with normal CSF $(38.5 \%)$ than in the abnormal group (30\%). Past history: febrile convulsions were not found in any case with abnormal CSF, but $6 \%$ of the other group had a history of their occurrence. No significant difference appeared concerning past history of epileptic fits. Family history: convulsions seemed to be present more in cases with abnormal lumbar puncture $(20 \%)$ than the cases with normal results $(7.7 \%)$ (Table 4$)$.

\subsubsection{Description of fever}

Temperatures less than $39^{\circ} \mathrm{C}$ were present more in patients with normal CSF $(37 \%)$ than in patients with abnormal CSF (20\%); just the opposite was found for temperatures of $39^{\circ} \mathrm{C}$ and higher (Table 5).

Table 4. Comparison between patients with normal CSF and those with abnormal CSF according to convulsion

\begin{tabular}{|c|c|c|c|c|}
\hline \multicolumn{2}{|l|}{ Convulsion } & Normal CSF [n (\%)] & Abnormal CSF [n (\%)] & p-value \\
\hline \multirow[t]{5}{*}{ Duration } & $<15$ minutes & $23(35.38)$ & $2(10)$ & \multirow[t]{5}{*}{0.33} \\
\hline & 15 minutes -24 hours & $25(38.460$ & $8(40)$ & \\
\hline & $1-3$ day & $10(15.38)$ & $6(30)$ & \\
\hline & 3-7 day & $6(9.23)$ & $3(15)$ & \\
\hline & $\geq 7$ days & $0(0.00)$ & $1(5)$ & \\
\hline \multirow[t]{3}{*}{ Type } & Generalized & $60(92.31)$ & $15(75)$ & \multirow[t]{3}{*}{0.08} \\
\hline & Focal or localized & $3(4.62)$ & $4(20)$ & \\
\hline & $\begin{array}{l}\text { Focal with secondary } \\
\text { generalization }\end{array}$ & $2(3.08)$ & $1(5)$ & \\
\hline \multirow{2}{*}{$\begin{array}{l}\text { Recurrence during } \\
\text { the same illness }\end{array}$} & Present & $39(60)$ & $16(80)$ & \multirow[t]{2}{*}{0.10} \\
\hline & Not present & $26(40)$ & $4(20)$ & \\
\hline \multirow[t]{4}{*}{ Preceding illness } & None & $33(50.77)$ & $13(65)$ & \multirow[t]{4}{*}{0.46} \\
\hline & Gastroenteritis & $25(38.46)$ & $6(30)$ & \\
\hline & URTI & $2(3.08)$ & $1(5)$ & \\
\hline & LRTI & $597.69)$ & $0(0.00)$ & \\
\hline \multirow[t]{3}{*}{ Past history } & None & $56(86.15)$ & $19(95)$ & \multirow[t]{3}{*}{0.47} \\
\hline & Of febrile convulsions & $4(6.15)$ & $0(00)$ & \\
\hline & Of convulsions (epilepsy) & $5(7.69)$ & $1(5)$ & \\
\hline \multirow{2}{*}{$\begin{array}{l}\text { Family history of } \\
\text { convulsions }\end{array}$} & Not present & $60(92.31)$ & $16(80)$ & \multirow[t]{2}{*}{0.12} \\
\hline & Present & $5(7.69)$ & $4(20)$ & \\
\hline
\end{tabular}


Table 5. Comparison between patients with normal CSF and those with abnormal CSF according to fever

\begin{tabular}{|l|l|l|l|l|}
\hline Characteristics & Normal CSF [n (\%)] & Abnormal CSF [n (\%)] & p-value \\
\hline \multirow{2}{*}{ Fever } & Low grade & $15(23.07)$ & $2(10)$ & 046 \\
\cline { 2 - 5 } & High grade & $50(76.92)$ & $18(90)$ & \\
\hline \multirow{2}{*}{$\begin{array}{l}\text { Fever duration } \\
\text { (day) }\end{array}$} & $<1$ & $16(24.62)$ & $2(10)$ & 0.27 \\
& $1-3$ & $23(35.38)$ & $8(40)$ & \\
\cline { 2 - 5 } & $3-7$ & $19(29.23)$ & $5(25)$ & \\
\cline { 2 - 5 } & $\geq 7$ & $7(10.77)$ & $5(25)$ & \\
\hline
\end{tabular}

3.9.3. Other presenting symptoms

Diarrhea occurred in $40 \%$ of patients with normal CSF and in $30 \%$ of patients with abnormal CSF. There was no significant difference in the occurrence of vomiting and respiratory symptoms between the two groups.

3.9.4. Neurological examination

Signs of increased intracranial pressure were not present in any of the cases with normal yield of lumbar puncture. However, such signs were found in $10 \%$ of patients with CSF Pleocytosis. Also signs of meningeal irritation were apparent and clear in half of the patients with abnormal CSF, whereas only $12 \%$ of patients who had normal CSF had this symptom. Signs of lateralization occurred in 5\% of patients in the abnormal group and in $1.5 \%$ of the normal group (Table 6).

3.9.5. CT brain

CT brain abnormalities were found in $63.6 \%$ of patients with CSF pleocytosis, whereas they were found in only $12 \%$ of the patients with normal CSF (Table 7 ).

Table 6. Comparison between patients with normal CSF and those with abnormal CSF according to Neurological examination

\begin{tabular}{|c|c|c|c|c|}
\hline \multicolumn{2}{|l|}{ Characteristics } & $\begin{array}{l}\text { Normal CSF } \\
{[\mathrm{n}(\%)]}\end{array}$ & $\begin{array}{l}\text { Abnormal CSF } \\
{[\mathrm{n}(\%)]}\end{array}$ & p-value \\
\hline \multirow{3}{*}{$\begin{array}{l}\text { Conscious level (Glasgow coma } \\
\text { scale) }\end{array}$} & $15 / 15$ & $29(44.62)$ & $6(30)$ & \multirow[t]{3}{*}{0.21} \\
\hline & $8-15 / 15$ & $2843.08)$ & $13(65)$ & \\
\hline & $3-7-15$ & $8(12.31)$ & $1(5)$ & \\
\hline \multirow{2}{*}{$\begin{array}{l}\text { Signs of increased intracranial } \\
\text { pressure }\end{array}$} & Not present & $65(100)$ & $18(90)$ & \multirow[t]{2}{*}{0.01} \\
\hline & Present & $0(0.00)$ & $2(10)$ & \\
\hline \multirow[t]{3}{*}{ Signs of meningeal irritation } & Not present & $57(87.69)$ & $10(50)$ & \multirow[t]{3}{*}{0.01} \\
\hline & Neck rigidity \&/or retraction & $7(10.77)$ & $7(35)$ & \\
\hline & 2+ Positive Brudziniski sign & $1(1.54)$ & $3(15)$ & \\
\hline \multirow[t]{2}{*}{ Signs of lateralization } & Not present & $64(98.46)$ & $19(95)$ & \multirow[t]{2}{*}{0.37} \\
\hline & Present & $1(1.54)$ & $1(5)$ & \\
\hline
\end{tabular}

Table 7. Comparison between patients with normal CSF and those with abnormal CSF according to CT brain results

\begin{tabular}{|l|l|l|l|l|}
\hline \multicolumn{2}{|l|}{ CSF findings } & $\begin{array}{l}\text { Normal CSF } \\
{[\mathrm{n}(\%)]}\end{array}$ & $\begin{array}{l}\text { Abnormal CSF } \\
{[\mathrm{n}(\%)]}\end{array}$ & p-value \\
\hline \multirow{2}{*}{ Brain CT scan } & Not done & $40(61.54)$ & $9(45)$ & 0.19 \\
\cline { 2 - 5 } & done & $25(38.46)$ & $11(55)$ & \\
\hline \multirow{3}{*}{$\begin{array}{l}\text { Results of CT brain if } \\
\text { done }\end{array}$} & Normal & $22(88)$ & $4(36.36)$ & 0.02 \\
\cline { 2 - 5 } & Abnormal (localized hypodense area(s) & $1(4)$ & $1(9.09)$ \\
\cline { 2 - 5 } & Abnormal (brain edema) & $1(4)$ & $4(36.36)$ \\
\cline { 2 - 5 } & Abnormal (diffuse brain atrophy) & $1(4)$ & $1(9.09)$ \\
\cline { 2 - 5 } & Abnormal (hydrocephalus) & $0(0.00)$ & $1(9.09)$ \\
\hline
\end{tabular}

\section{Discussion and conclusions}

Infants and children presenting with fever and convulsions represent a relatively common emergency faced in outpatients as well as emergency section of the pediatric department. The aim of the evaluation of these patients was to clarify the diagnosis and to give appropriate therapy. The main question to be answered in this situation is whether the child has meningitis (14). Examination of cerebrospinal fluid (CSF) is very essential for accurate diagnosis of acute bacterial meningitis (ABM) (15). The present study performed a clinical analysis and reviewed the data of 85 infants and children presenting with fever and convulsions regarding history taking and clinical 
examination with special consideration for description of convulsions and presence of clinical signs suggesting CNS infection. Examination of CSF was performed for all cases to detect those having CNS infection. The idea was to determine the prevalence of CNS infection and especially acute bacterial meningitis in infants and children who present with fever and convulsions, by presence of CSF pleocytosis, and to correlate this diagnosis to their clinical profile. We noticed that the great majority of cases belonged to the youngest age group (one month to two years), reflecting the common occurrence of convulsions with fever in this age group. The median age was 19.9 months, and this was similar to Ghotbi and Shiva's study in which the median age was 19.3 months (16). ABM was defined as growth of a pathogen from a CSF specimen obtained within one week of presentation (14). CSF cultures were conducted for cases that had a WBC count coinciding with ABM (1000-10000/HPF) only. Three cases were diagnosed to have $\mathrm{ABM}$ by this definition i.e., $3.5 \%$ of all cases. This percentage was higher than it was in the following studies, i.e., Ghotbi and Shiva's study, in which ABM was diagnosed in $2 \%$ of the studied cases (16); Kimia's study, in which ABM was found in $0.9 \%$ of the studied cases (14); and Fletcher and Sharieff's study, in which $\mathrm{ABM}$ was discovered in $0.5 \%$ of the cases (17).

The possible explanation of the higher percentage of cases of ABM in our study is that our study included all cases that presented with fever and convulsions, including cases with their first complex febrile seizures, as was the case in Kimia's and Fletcher's studies, and our study included a wider range of age groups, whereas the other three studies included only cases from six months to five years (60 months); our study was performed on a smaller number of cases, and it was conducted in a governorate in Upper Egypt that was characterized by low socioeconomic conditions and the common occurrence of infectious and contagious diseases. A very important point is that the mentioned studies were performed on cases with a very high percentage of up-to-date vaccination coverage (98\% in Kimia's Study and $97.8 \%$ in Fletcher's study). However, our obligatory expanded program of vaccination did not cover the pathogens commonly implicated in the etiology of ABM. However, when we compared our results to those of studies performed in developing countries, our figures were comparable or even lower; in a study performed in Nigeria by Akpede and Sykes, ABM was diagnosed in $4.2 \%$ of cases (18). In another study in Nepal conducted by Joshi Batajoo et al., ABM was present in $4.5 \%$ of cases (19). In our study, meningoencephalitis (non-bacterial) was detected in $20 \%$ of the studied cases. The last mentioned study had that the nearest results to ours was Fletcher's study (11\%). Our value was larger than the other studies, and this may be due to the same causes mentioned earlier. Concerning the isolated organism, the three cases revealed streptococcus pneumoniae on CSF culture, and this was similar to that found in Kimia's study (14). When the clinical profile is considered, there was a statistical significance correlating the presence of signs of meningeal irritation and signs of increased intracranial pressure to the presence of abnormal CSF white blood cell count. Meningeal irritation was present in many cases diagnosed with viral meningoencephalitis and in all cases diagnosed with bacterial meningitis. This statistical significance is also present in all of the mentioned studies, despite the limited resources that hindered us from performing CSF cultures for all cases with CSF Pleocytosis. This study found that, in infants and children presenting with fever and convulsions, CNS infections are not an uncommon disease in our locality, and acute bacterial meningitis cannot be excluded. However its presence in the absence of clinical symptoms and signs of meningeal irritation is a remote possibility, but it should always be considered. So our recommendation is to inform pediatricians in our locality to raise their clinical suspicion for CNS infections and lumbar puncture should be done for cases with clinical manifestations of meningitis or in the presence of risk factors suggested by other studies and guidelines, such as prior antibiotic use (as partially treated meningitis may be present) and age younger than one year (as signs of meningitis are insensitive in this age group). This may reduce chronic neurological disabilities following CNS infections.

\section{Acknowledgments:}

The authors thank all children and their parents for their kind participation in the study.

\section{Conflict of Interest:}

There is no conflict of interest to be declared.

\section{Authors' contributions:}

All authors contributed to this project and article equally. All authors read and approved the final manuscript.

\section{References:}

1) Sahu RN, Kumar R, Mahapatra AK. Central nervous system infection in the pediatric population. J Pediatr Neurosci. 2009; 4(1): 20-4. doi: 10.4103/1817-1745.49102. PMID: 21887170 , PMCID: PMC3162832. 
2) Thomson RB Jr, Bertram H. Laboratory diagnosis of central nervous system infections. Infect Dis Clin North Am. 2001; 15(4): 1047-71. doi: 10.1016/S0891-5520(05)70186-0. PMID: 11780267.

3) Dawson KG, Emerson JC, Burns JL. Fifteen years of experience with bacterial meningitis. Pediatr Infect Dis J. 1999; 18(9): 816-22. doi: 10.1097/00006454-199909000-00014. PMID: 10493344.

4) Centers for Disease Control and Prevention (CDC). Progress toward eliminating Haemophilus influenza type b disease among infants and children-United States, 1998-2000. Morb Mortal Wkly Rep. 2002; 51(11): 234-7. PMID: 11925021.

5) El Bashir H, Laundy M, Booy R. Diagnosis and treatment of bacterial meningitis. Arch Dis Child. 2003; 88(7): 615-20. doi: 10.1136/adc.88.7.615. PMID: 12818910, PMCID: PMC1763168.

6) Freedman SB, Marrocco A, Pirie J, Dick PT. Predictors of bacterial meningitis in the era after Haemophilus influenzae. Arch Pediatr Adolesc Med. 2001; 155(12): 1301-6. doi: 10.1001/archpedi.155.12.1301. PMID: 11732947.

7) Llorens SX, McCracken GH Jr. Bacterial meningitis in children. Lancet. 2003; 361(9375): 2139-48. doi: 10.1016/S0140-6736(03)13693-8.

8) Sturgis CD, Peterson LR, Warren JR. Cerebrospinal fluid broth culture isolates: their significance for antibiotic treatment. Am J Clin Pathol. 1997; 108(2): 217-21. doi: 10.1093/ajcp/108.2.217. PMID: 9260764.

9) Solomon T, Hart IJ, Beeching NJ. Viral encephalitis: a clinician's guide. Pract Neurol. 2007; 7(5): $288-$ 305. doi: 10.1136/jnnp.2007.129098. PMID: 17885268.

10) Olofsson IA, Skov L, Miranda MJ. (Acute disseminated encephalomyelitis is an important differential diagnosis in the acutely affected child). Ugeskr Laeger. 2015; 177(29).

11) Kneen R, Solomon $T$, Appleton R. The role of lumbar puncture in children with suspected central nervous system infection. BMC Pediatr. 2002; 2: 8. doi: 10.1186/1471-2431-2-8. PMID: 12350236, PMCID: PMC126268.

12) Chataway J, Davies NW, Farmer S, Howard RS, Thompson EJ, Ward KN. Herpes simplex encephalitis: an audit of the use of laboratory diagnostic tests. QJM. 2004; 97(6): 325-30. doi: 10.1093/qjmed/hch058. PMID: 15152105.

13) Maschke M, Kastrup O, Forsting M, Diener HC. Update on neuroimaging in infectious central nervous system disease. Curr Opin Neurol. 2004; 17(4): 475-80. doi: 10.1097/01.wco.0000137540.29857.bf. PMID: 15247545 .

14) Kimia A, Ben-Joseph EP, Rudloe T, Capraro A, Sarco D, Hummel D, et al. Yield of lumbar puncture among children who present with their first complex febrile seizure. Pediatrics. 2010; 126(1): 62-9. doi: 10.1542/peds.2009-2741. PMID: 20566610.

15) Kimia AA, Capraro AJ, Hummel D, Johnston P, Harper MB. Utility of lumbar puncture for first simple febrile seizure among children 6 to 18 months of age. Pediatrics. 2009; 123(1): 6-12. doi: 10.1542/peds.2007-3424. PMID: 19117854.

16) Ghotbi F, Shiva F. An assessment of the necessity of lumbar puncture in children with seizure and fever. J Pak Med Assoc. 2009; 59(5): 292-5. PMID: 19438132.

17) Fletcher EM, Sharieff G. Necessity of lumbar puncture in patients presenting with new onset complex febrile seizures. West J Emerg Med. 2013; 14(3): 206-11. doi: 10.5811/westjem.2012.8.12872. PMID: 23687537, PMCID: PMC3656699.

18) Akpede GO, Sykes RM. Convulsions with fever as a presenting feature of bacterial meningitis among preschool children in developing countries. Dev Med Child Neurol. 1992; 34(6): 524-9. doi: 10.1111/j.1469-8749.1992.tb11473.x. PMID: 1612211.

19) Joshi Batajoo R, Rayamaihi A, Mahaseth C. Children with first episode of fever with seizure: is lumbar puncture necessary? Nepal Med Assoc. 2008; 47(171): 109-12. PMID: 19079373. 